\title{
Solid and Resourceful Micro-Strip Feed Monopole Antenna for WirelessLAN Appliance
}

\author{
K.Aswin ${ }^{1}$,R.Sureshkumar ${ }^{2}$, S.Sowbakkiyam PG Scholars ${ }^{1,2,3}$, \\ Department of Electronics and Communication Engineering \\ Bannari Amman Institute of Technology, Sathymangalam,Erode.
}

\begin{abstract}
A single band Solid micro-strip Feed monopole antenna for Wireless Local Area Network (WLAN) application is presented. The proposed antenna design consists of a Y-Shaped monopole antenna with the ring slot and a designed rectangular slot which surrounds the monopole antenna. The experimental result shows that the proposed single band antenna has a return loss of $-22.147 \mathrm{~dB}$ and band widthisl.2 $\mathrm{GHz}$ which lies at a frequency range of about $5.0 \mathrm{GHz}$ to $6.2 \mathrm{GHz}$ tuned at a centre frequency of $5.8 \mathrm{GHz}$, which can cover the WLAN-5.8 GHz frequency band then, the related radiation patterns have been observed at $5.8 \mathrm{GHz}$. The gain and efficiency of a proposed antenna is $4.43167 \mathrm{dBi}$ and $80.698 \%$.

Index Terms: WLAN, Rectangular slot, Ring slot, Micro-strip Feed, Single band, Monopole antenna.
\end{abstract}

\section{Introduction}

Nowadays, most of the wireless communication systems such as the Wireless Local Area Network (WLAN) and the Worldwide Interoperability for Microwave Access (WiMAX), many interests are focused on the design of antennas with characteristics of Solid size, sufficient impedance bandwidth, Omni-directional pattern, gain, efficiency etc. To meet these requirements, various types of antenna designs have been reported [1]-[10]. The proposed monopole antenna, which has different configuration Split-Ring Slot[2], a wide open Uslot antenna with combination of symmetrical L-strips [4], Meandered T-shaped monopole antenna[5], Dualband CPW-Feed Y-shaped monopole antenna [6], and the CPW-Feed equilateral triangular-ring slot antennas [7].

In this letter, a relatively Resourceful single band monopole antenna is presented for WLAN application. Measurement shows that the antenna can effectively cover the bandwidth of $0.6 \mathrm{GHz}(5.5 \mathrm{GHz}-6.1$ $\mathrm{GHz}$ ), which satisfy the requirement both $5.8 \mathrm{GHz}$ WLAN bands. The antenna provides a impedance bandwidth of $0.6 \mathrm{GHz}$ with corresponding frequency band $5.50-6.10 \mathrm{GHz}$, centered at $5.80 \mathrm{GHz}$, respectively. Although above antenna has many advantages, and there are some performances can be improved. The designs of antenna may increase cost or complexity for practical terminal design in [2][3]; or the overall dimensions of antenna are with large size in [7] and [10] compared to proposed antenna, which possibly limit the integration level of the future wireless communication system.

The effect of the antenna's key structural parameters on its performance was also analyzed.In section 2, the various design process and optimal structure of the proposed antenna are presented. In section 3 , simulation results are presented, where the Resourceful single band operation performances of the antenna are given and discussed. In section 4 , the brief conclusions for the proposed system are given.

\section{Antenna Design}

To achieve an effective single band operation for WLAN application from proposed antenna design. The antenna is simulated by using the FR4 substrate with the dielectric constant of 4.6, TanDof 0.025 and the thickness of the substrate is $1.6 \mathrm{~mm}$. The copper conductor is placed on the FR4 substrate, which has the thickness of $0.3 \mathrm{~mm}$. Then, the feeding line is given to the bottom side of an antenna which has the characteristics impedance of $50 \mathrm{ohm}$. The design process of a proposed antenna is shown in Figure 1. 


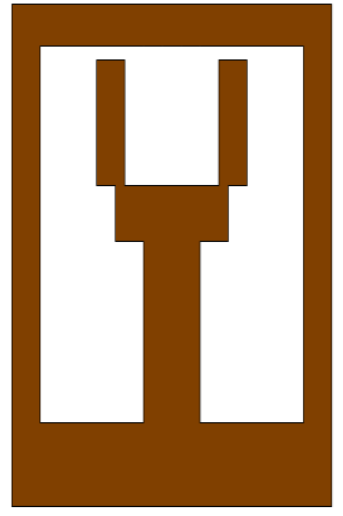

Antenna 1

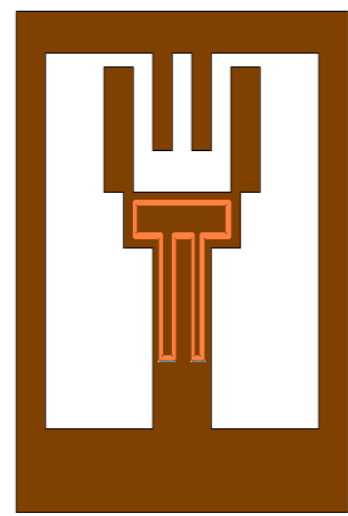

Antenna 2

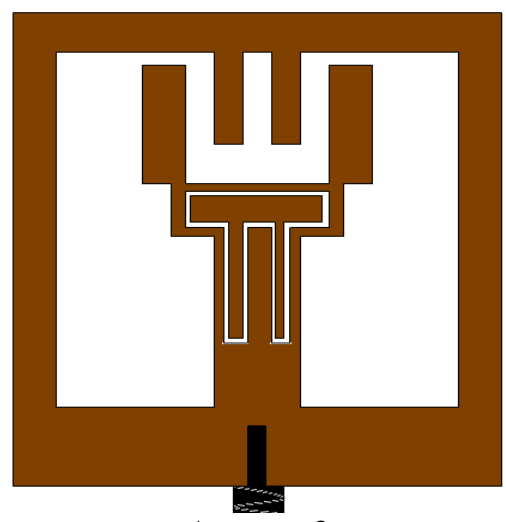

Antenna 3

Fig. 1. Various design process of proposed Antenna.

In this proposed antenna contains three shapes, first one is monopole antenna which is in the shape of Y-shaped slot surrounds by the rectangular slot. Second antenna is a small n-shaped cut, and it placed at top of the $\mathrm{Y}$ shaped slot, and the split ring slot placed on the Y-shaped part of the first antenna. Then, the Y-shaped structure extruded by using the split ring slot. Antenna three (proposed antenna) contains all the rectangular slot, n-shaped cut and extruded Y-shaped slot by using the split ring slot. Thus, the third antenna achieves the Resourceful single band operation at $5.8 \mathrm{GHz}$ for a WLAN application. Then the design configuration for an Antenna 3 (Proposed antenna) is presented in Figure 2.

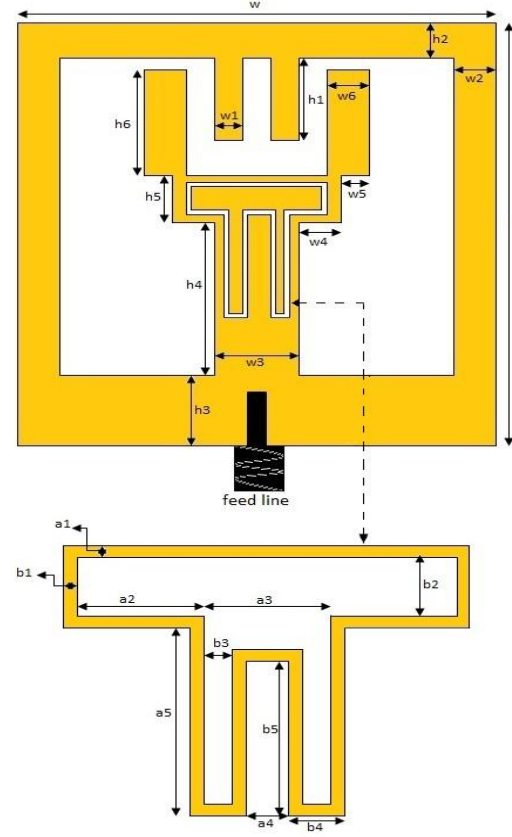

Fig. 2. Geometry of proposed antenna 
The dimensions of a proposed antenna are as follows:

\begin{tabular}{|c|c|}
\hline \multicolumn{1}{|c|}{ Parameters } & Dimensions $(\mathbf{m m})$ \\
\hline W & 15 \\
\hline w1 & 2 \\
\hline w2 & 3 \\
\hline w 4 & 7 \\
\hline w5 & 1 \\
\hline w6 & 2 \\
\hline H & 22 \\
\hline h1 & 5 \\
\hline h2 & 2 \\
\hline h3 & 4 \\
\hline h4 & 2 \\
\hline h5 & 3 \\
\hline h6 & 5 \\
\hline a1 & 0.1 \\
\hline a2 & 1.8 \\
\hline a3 & 2.0 \\
\hline a5 & 0.4 \\
\hline b1 & 6 \\
\hline b2 & 0.1 \\
\hline b3 & 1.8 \\
\hline b4 & 0.2 \\
\hline b5 & 0.4 \\
\hline
\end{tabular}

Table. 1. Optimal dimensions of the designed antenna.

By suitable tuning the geometry parameters of this proposed antenna independently, an Resourceful single band antenna suitablefor WLAN operation at the frequency range of $5.8 \mathrm{GHz}$ is achieved. The antenna performance was simulated using ADS (Advanced Designing System) is prior to its fabrication. The simulated results presented show good agreement.

\section{Results and Discussion}

Based on the structure of the proposed model, an antenna prototype is simulated. The simulated return loss against the suitable frequency, with the proposed antenna can be resulted. In this proposed antenna, that the split-ring slot could improve the performance at the frequency range of $5.8 \mathrm{GHz}$ band.

After simulation, the resulted return loss is shown in Fig. 3, here the impedance bandwidths for $-22.147 \mathrm{~dB}$ return loss of the individual operating band is about $900 \mathrm{MHz}(5.3 \mathrm{GHz}$ to $6.2 \mathrm{GHz})$, which covering the centre frequency at $5.8 \mathrm{GHz}$ for WLAN operation band.

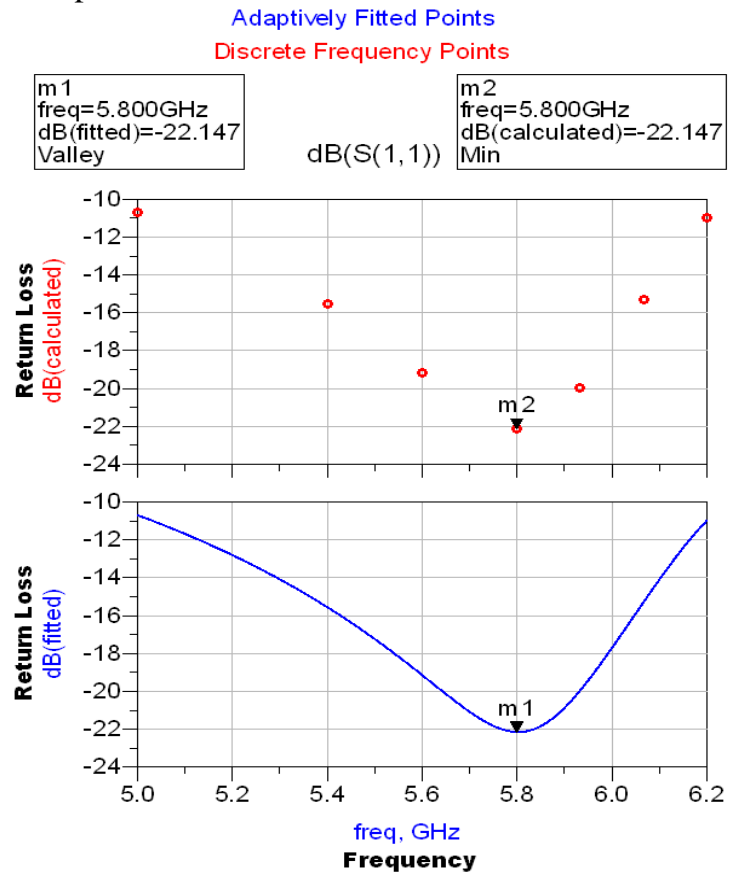

Fig. 3.Simulated return loss for proposed antenna 
Table. 2 show that the different return losses at corresponding frequencies:

\begin{tabular}{|c|c|}
\hline Frequency $(\mathbf{G H z})$ & Return Loss $(\mathbf{d B})$ \\
\hline 5.0 & -10.695 \\
\hline 5.2 & -13.282 \\
\hline 5.4 & -15.553 \\
\hline 5.6 & -19.145 \\
\hline 5.8 & -22.147 \\
\hline 5.9 & -19.947 \\
\hline 6.0 & -15.295 \\
\hline 6.2 & -10.991 \\
\hline
\end{tabular}

Table. 2. Return loss analysis

The power excitation mechanism of the proposed antenna scenario is shown in Fig. 4, the simulated proposed antenna produced surface currentat the WLAN operating frequency band of $5.8 \mathrm{GHz}$.

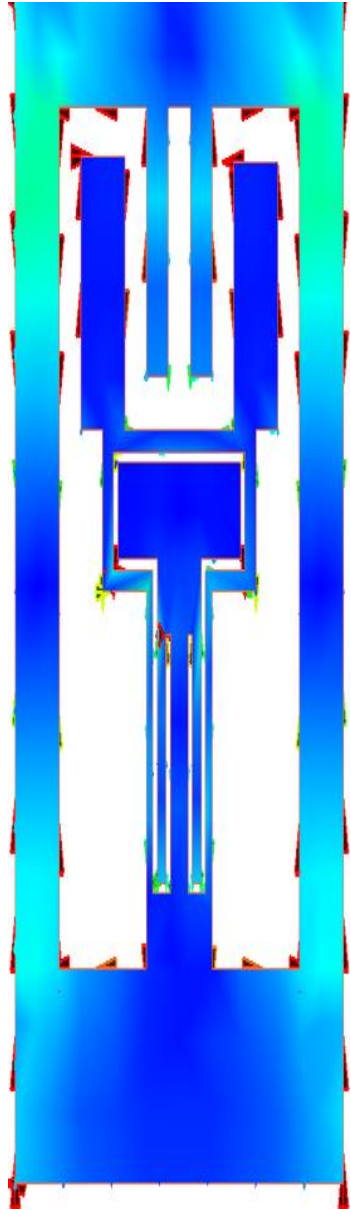

(a) Before radiation

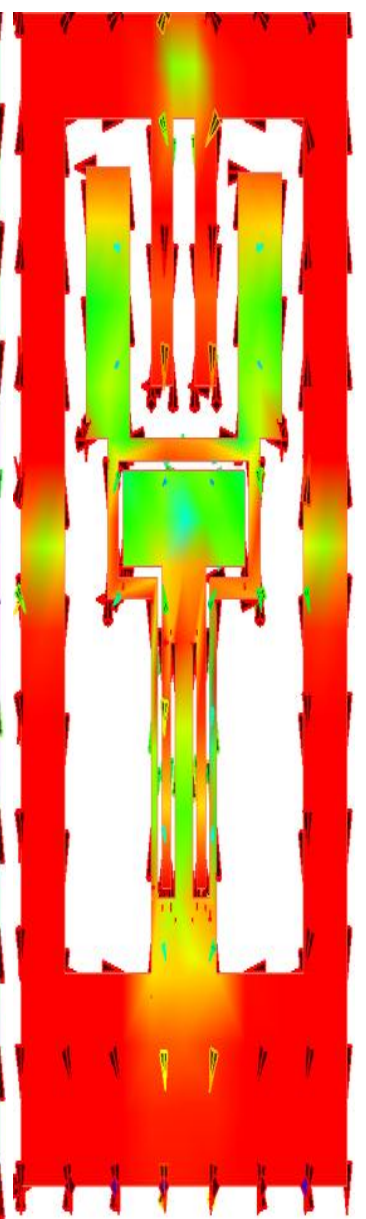

(b) After radiation

Fig. 4.Surface current distribution and radiations of a proposed antenna.

In Fig. 4(a) and 4(b), blue color represents the no radiation at the starting point of the power distribution, green and red color indicates the minimum and maximum radiation during the effective power distribution. The current distributes mainly along the designed rectangular slot at $5.8 \mathrm{GHz}$. And the modified rectangular slot acts as a resonator for the lower resonance generation.

At $5.8 \mathrm{GHz}$, the far field radiation pattern of the simulated antenna is shown in Fig. 5, here the field radiated at all the four sides of the plot and which produces the Resourceful far field antenna parameters. 


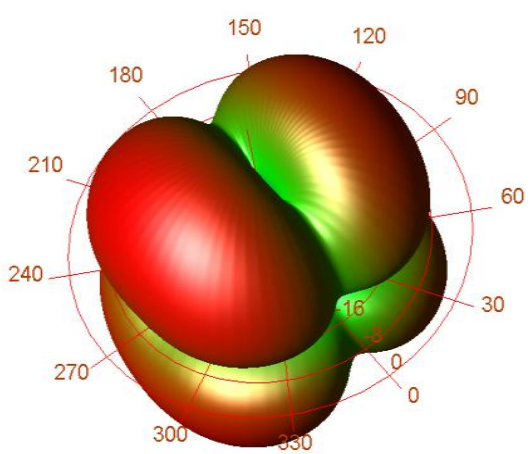

Fig. 5. Overall far field radiation pattern.

The Fig. 6 shows the far field cut of the simulated radiation pattern. The resulted antenna parameters are, the radiated power is 0.219405 watts at the effective angle 3.65518steradianswhich produces the gain of 4.43167 $\mathrm{dBi}$ and the directivity is $5.36302 \mathrm{dBi}$. The efficiency of the proposed antenna is $80.698 \%$.
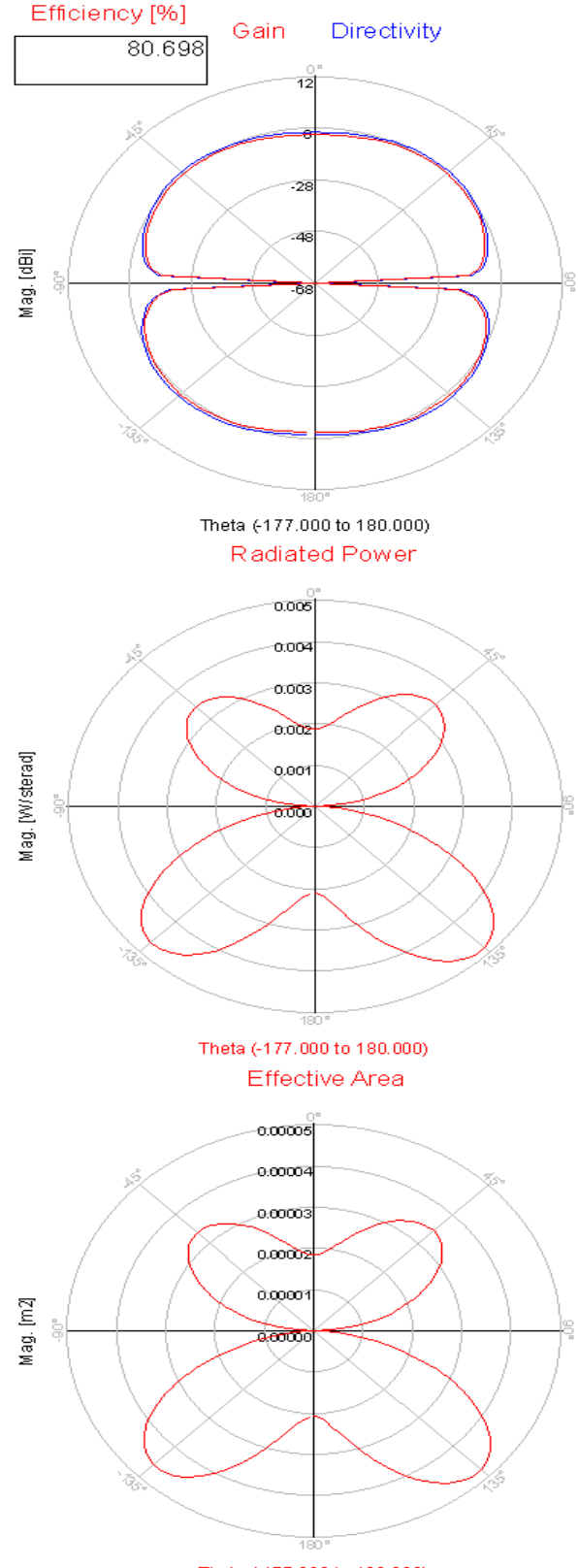

(a) Power 

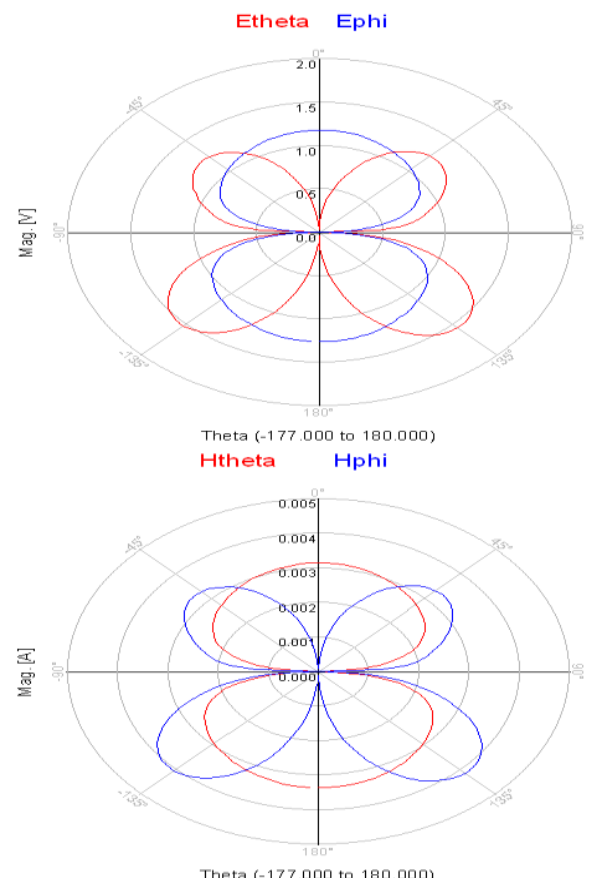

(b) Absolute fields

E_left E_right

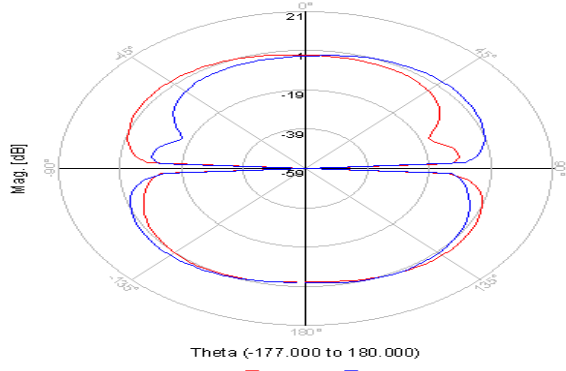

E_co E_cross



(c) Circular and linear polarization

Fig. 6. Far field cut of the simulated radiation pattern.

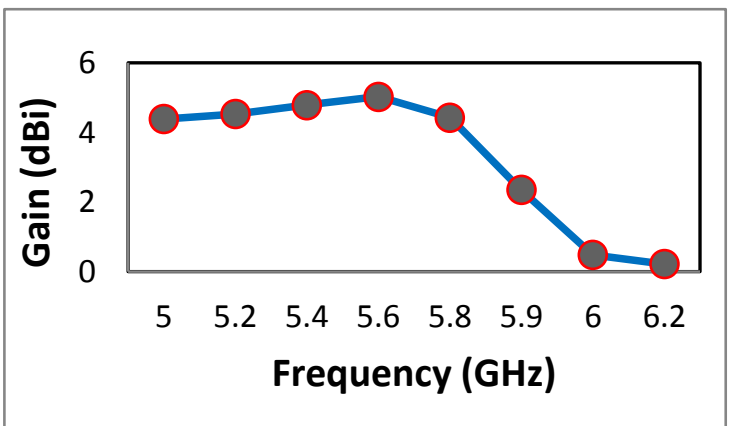

Fig. 7. Gain vs Frequency plot. 
These far field radiation characteristics and antenna parameters are revealed that the proposed antenna is suitable and competent for the Wireless Local Area Network (WLAN) application.

\section{Conclusion}

A new micro-strip Feed Resourceful single band monopole antenna has been proposed. By employing and exercising various types of resonant antenna structures in the scenario and later extruding a split ring slot in the $y$-shaped structure of the monopole antenna the design has been proposed. The proposed antenna can obtain the Resourceful single band operation in between the frequency range of $5.0 \mathrm{GHz}$ to $6.2 \mathrm{GHz}$, which can cover the centre frequency at $5.8 \mathrm{GHz}$ band for WLAN application. The layout of the proposed antenna is designed, and then simulated. The observed results show reasonable agreement, due to the better radiation pattern performance and achieves the effective gain in the required band, the proposed antenna is suitable and competent for WLAN application.

\section{References}

[1] “A Soild Printed Antenna for WLAN/WiMAX Applications"HuiqingZhai, Member IEEE, Zhihui Ma, Yu Han, and Changhong Liang, Senior Member, IEEE Copyright (c) 2013 IEEE.

[2] "Soild CPW-FeedTri-Band Printed Antenna with Meandering Split Ring Slot for WLAN and WiMAX Applications"Pingan Liu, YanlinZou, BaorongXie, Xianglong Liu, and Baohua Sun,IEEE Antennas and Wireless Prop.Lett, Vol.11, 2012.

[3] W.C.Liu, C.M.Wu, and N.C.Chu, "A Soild CPW-Feed slotted patch antenna for dual band operation," IEEE Antennas WirelessPropag.Lett., vol.9, pp.595-598, 2010.

[4] W.Hu, Y.Z.Yin, X.Yang, K.Song, Z.Y.Liu and L. H.Wen, “A wide open U-slot antenna with a pair of symmetrical L-strips for WLAN applications," Prog. Electromagn. Res. Lett., vol.16, pp.141-149, 2010.

[5] T.N.Chang and J.H.Jiang, "Meandered T-shaped monopole antenna," IEEE Trans. Antennas Propag., vol.57, no.12, pp.3976-3978, Dec.2009.

[6] W.C.Liu and C.F.Hsu, "Dual band CPW Feed Y-shaped monopole antenna for PCS/WLAN application," Electron.Lett., vol.41, pp.390-391, 2005.

[7] J.S.Chen, "Studies of CPW Feed equilateral triangular ring slot antennas and triangular ring slot coupled patch antennas," IEEE TransAntennas Propag., vol.53, no.7, pp.2208-2211, Jul.2005.

[8] R.Karimian, M.Soleimani, and S.M.Hashemi, "Tri Band Four Elements MIMO Antenna System for WLAN and WiMAX Application," Electromagnetic Wave and Application, Vol.26, Nos.17-18, 2348-2357, 2012.

[9] W.Hu, Y.Z.Yin, X.Yang and X.S. Ren, "Soild printed antenna with shaped stub for dual band operation," Electron. Lett., vol.46, pp.1644-1645, 2010.

[10] J.Jung, W.Choi, and J.Choi, “A small wideband microstripFeed monopole antenna," IEEE Microwave, Wireless Compon.Lett., vol.15, no.10, pp.703-705, Oct.2005. 